\title{
Cryptocurrency Acceptance: A Case of Malaysia
}

\author{
Yoon-Chow Yeong, Khairul Shafee Kalid, Savita K Sugathan
}

\begin{abstract}
Since the inception of the first cryptocurrency in 2008 , cryptocurrency has been receiving global attention from the public, media, merchants and regulators. Although the general sentiment suggested cryptocurrencies which leverage on blockchain technology might eventually replace the paper currency as the mainstream currency, the Malaysian regulators are still unsure that a well-established cryptocurrency ecosystem can come into place anytime soon. Unfortunately, there is a lack of cryptocurrency acceptance study, particularly in Malaysia (developing country context). Hence, this paper aims to propose a research model that integrates cryptocurrency dimension antecedents with Unified Theory of Acceptance and Use of Technology2 (UTAUT2) constructs to examine the factors that influence cryptocurrency acceptance. This study employs a quantitative approach by collecting online survey questionnaire data through the means of cryptocurrency community group on social media. The survey instrument was reviewed by four experts from the field of blockchain and 36 responses have been gathered from individuals who have cryptocurrency knowledge for pilot study. To further evaluate the reliability and validity of the proposed measures, the measurement model was assessed using structural equation modeling (SEM) technique with partial least square approach (PLS). SmartPLS software was used for PLSSEM analyses. In this paper, the proposed research model contributes a high-level overview of and valuable insights into the potential cryptocurrency acceptance factors to regulatory bodies, practitioners as well as prospective cryptocurrency users. The findings of pilot study confirm that the measurement items and constructs in the proposed model are reliable and valid.
\end{abstract}

Index Terms: Blockchain, Cryptocurrency, Developing Country, Pilot Study

\section{INTRODUCTION}

In the arc of modern technology development, the digitization of the economy has provided benefits in economic growth and transforms economic activities to be more effective and flexible. Malaysia's business news had reported that digital economy's impact on gross domestic product is anticipated to rapidly increase by RM 400 billion by 2025 [1]. In the world of the digital economy, the harnessing of financial technologies [2] is radically changing the ways of delivering financial services, especially payment system. Since a decade ago, blockchain technology has emerged in FinTech field that underlies the advent of cryptocurrencies [2] such as Bitcoin, Ethereum, Ripple and others. Cryptocurrency is "a token created and stored electronically in blockchain to control the creation of monetary units and to verify the transactions" [3].

Revised Manuscript Received on April 19, 2019.

Yoon-Chow Yeong, MSc degree student Information Systems Computer and Information Sciences, Department of the University Teknologi, PETRONAS (UTP), Malaysia

Dr Khairul Shafee Kalid, Senior lecturer, Computer and Information Systems department, Universitiy Teknologi, PETRONAS (UTP), Malaysia.

Dr Savita K Sugathan, lecturer, Computer and Information Systems department, Universitiy Teknologi PETRONAS (UTP), Malaysia
Nevertheless, the decentralized and anonymous nature of cryptocurrency has reduced governments' control in preventing cryptocurrency usage for illicit transactions. Along the years, laws and regulations relating to cryptocurrency frequently updated in many countries as technology evolves and cryptocurrency acceptance increases [4]. Up to 2018, Malaysia's position remains ambiguity as cryptocurrency is neither banned nor accepted as legal tender. Despite the mixture of positive and negative sentiment about cryptocurrency on the back of the news relating to hacking, decentralized blockchains, and regulations, there are significant amounts of Malaysians opt to accept cryptocurrency. In 2019, Malaysian government has shown their clear standpoint by introducing the cryptocurrency regulation which comes into effect on 15th January 2019. In the context of the Capital Markets and Services Order 2019, all digital currencies, tokens and crypto-assets are classified as securities which are placed under the authority of Securities Commissions. For any unauthorized initial coin offerings or digital asset exchanges in Malaysia, a 10-year jail will be sentenced and a RM 10 million will be fined [5]. Besides, the Malaysian Ministry of Finance asserted government's initiatives in supporting the continued development of digital asset and peer-to-peer financing while protecting investors in any case of digital assets trading.

While cryptocurrency is launched as a core evolution to FinTech field, a wide acceptance by individuals is the critical factor that drives the success of cryptocurrency as a payment mechanism [6]. Existing literature shows that cryptocurrency acceptance had been studied in the USA and Canada [7], Germany, Iceland and South Korea [8] as well as Austria, Switzerland, UK and Israel [9]. However, the empirical evidence on cryptocurrency acceptance research is still limited [10], especially in developing countries context [11] and the user perspective is disregarded [7, 12]. On top of that, [9] and [13] asserted that there is lack of study that discusses on cryptocurrency based on the intertwining of technological aspects and social contexts in which indicates it has not reached the mainstream in IS domain.

With the establishment of Malaysia governance structure, it is anticipated that cryptocurrency will still be around for the foreseeable future but there is a lack of acceptance study in Malaysia individual context. Therefore, the objective of this paper is to propose a research model utilizing UTAUT2 model as the theoretical foundation to examine the factors that contribute to cryptocurrency acceptance in Malaysia, a developing country. In addition to the proposed research model, a two-stage pilot study was conducted to assess the reliability and validity of the embedded measures and constructs. 


\section{LITERATURE REVIEW}

The following section presents a brief introduction of blockchain, cryptocurrency and Bitcoin. Next, the existing theories in the domain of technology acceptance and adoption are also depicted, along with its feasibility to be employed in cryptocurrency context.

\section{A. Blockchain, Cryptocurrency and Bitcoin}

There seems a widespread misconception about blockchain, cryptocurrency and Bitcoin. Blockchain is "a distributed database of records or a public ledger of all transactions or digital events that have been executed and shared among participants" [14]. Blockchain technology can property, law, logistics and supply chain $[6,12]$. Within the financial domain, cryptocurrency is an example that uses blockchain technology. Bitcoin is the first and most wellknown cryptocurrency which was introduced by Satoshi Nakamoto in 2008 [15]. Despite the rising popularity of Bitcoin with its spiking growth in value, it remains controversial if cryptocurrency should be gaining legitimacy for business transactions and investment [4]. The lack of a standard global regulatory framework for this emerging FinTech innovation had caused many people to take advantage of its decentralized nature for illegal purposes such as money laundering, illicit trade for weapons and drugs as well as financing terrorism [4].

\section{B. Technology Acceptance and Adoption Theories}

Within Information System (IS) domain, understanding acceptance of IT innovations is one of the most mainstream research areas and thus it is a continually developing research field. Since decades ago, significant technological changes have made various IS models and theories an essential analytical tool to explain technology acceptance and adoption, included but not restricted to, the Theory of Reasoned Action, Social Cognitive Theory, Technology Acceptance Model, TAM2, TAM3, Theory of Planned Behavior, Model of PC Utilization (MPCU), Innovation Diffusion Theory (IDT), Unified Theory of Acceptance and Use of Technology (UTAUT) and UTAUT2 [16].

The theories and models are reviewed to examine its feasibility to be adapted into the cryptocurrency acceptance context. TRA, SCT, and TPB emphasizes on social factors that impact a person's behavior. These three theories disregard technological factor which is important to cryptocurrency as it is a novel financial innovation and thus not suitable to be adopted in this research. TAMs are not addressing cryptocurrency acceptance. In addition, MPCU is not recommended because it specifically deals with the factors that influence a worker's use of computer at the workplace. Also, IDT is not suitable because this model requires static inputs and yet cryptocurrency is a relatively recent innovation which is frequently evolving.

The UTAUT model focuses on the organizational context and the model was originally validated by collecting data from employees in four organizations to study the acceptance of a new technology introduced to the workplace [17]. Besides, the concept of this theory emphasizes time and effort factor. This indicates a lack of consideration of be implemented in the different industry such as finance, suitable because their constructs lack comprehensiveness in

the money constraints that affect users' behavioral intention to adopt this digital form of currency which involves price and worth. Dated back in 2012, UTAUT model was revised and modified into UTAUT2 [18]. UTAUT2 model is an improved version of UTAUT in which the embedded constructs are found to be relevant to cryptocurrency consumer context, also it deals with both social and technological factors. Thus, UTAUT2 is employed as the base model because it is a comprehensive model which consists of seven constructs that found relevant to cryptocurrency context.

Currently, UTAUT2 has been successfully adopted to understand the acceptance of numerous technologies such as laboratory electronic portal for patients [19], internet banking application for elderly students [20], mobile internet for mobile users [21], Internet for elderly people [22], spectrum [23] and Google classroom for university students [24]. From the analysis of several existing UTAUT2 applications, it is noticeable that UTAUT2 model is supported by several hypothesized relationships in different contexts, either partially or fully. Extant literature has shown that the most significant factors driving behavior intention (BI) and use behavior (UB) are performance expectancy (PE), hedonic motivation (HM) and habit (HB). Besides, these literatures have demonstrated that survey instrument is the most recommended and widely used data collection tool to test the hypotheses in research that relevant to UTAUT2 model.

\section{PROPOSED RESEARCH MODEL}

The preceding literature has revealed that UTAUT and UTAUT2 are feasible to be used with extended constructs and the moderators were found not significant to be tested $[8,25,26]$. Reference [25] added that the application of UTAUT2 for cryptocurrency field is still scarce due to its recentness in IS literature. Hence, this study fills in the research gap by examining cryptocurrency acceptance in Malaysian context on the basis of UTAUT2 model.

UTAUT2 is a powerful model with higher explanatory power as compared to UTAUT [27]. Given the fact that UTAUT2 primarily deals with individual consumer context [18], its function is found to be relevance to examine the acceptance factors of cryptocurrency in Malaysia. The term "consumer" is defined as a person who purchases goods and services for personal use. This concept matches with the use of cryptocurrency which allows individuals to trade for services and goods for personal use. In addition to the seven key constructs defined in the original UTAUT2 model, a cryptocurrency dimension consists of three new variables is proposed in this study to form a research model.

Subsequently, this paper proposes a new research model which integrates cryptocurrency dimension variables into UTAUT2 to expand the scope and boundaries of the original UTAUT2 model in order to improve its predictive capability. Building on the UTAUT2 model, this paper suggests eliminating the three moderators, namely 'age', 'gender' and 'experience'. This is because the scope of this 
study does not deal with comparative analysis among different age groups and genders. Existing studies have either attested that moderators 'age' and 'gender' do not bring significant moderating effect towards the behavioral intention to adopt cryptocurrency or it was found not important to be tested in cryptocurrency context [7, 28]. Meanwhile, this study is not a longitudinal study that spans over different time periods and thus it is impractical to explore the effects of user experience level in user's attitude towards cryptocurrency.

\section{A. Conceptual Model}

In this section, a conceptual model is proposed as a visual representation of the relationships between endogenous and exogenous variables. The seven key constructs defined in the original UTAUT2 model and three cryptocurrency dimension variables are used to form a conceptual model towards the development of hypotheses statement. Fig. 1 displays the illustration of the conceptual model.

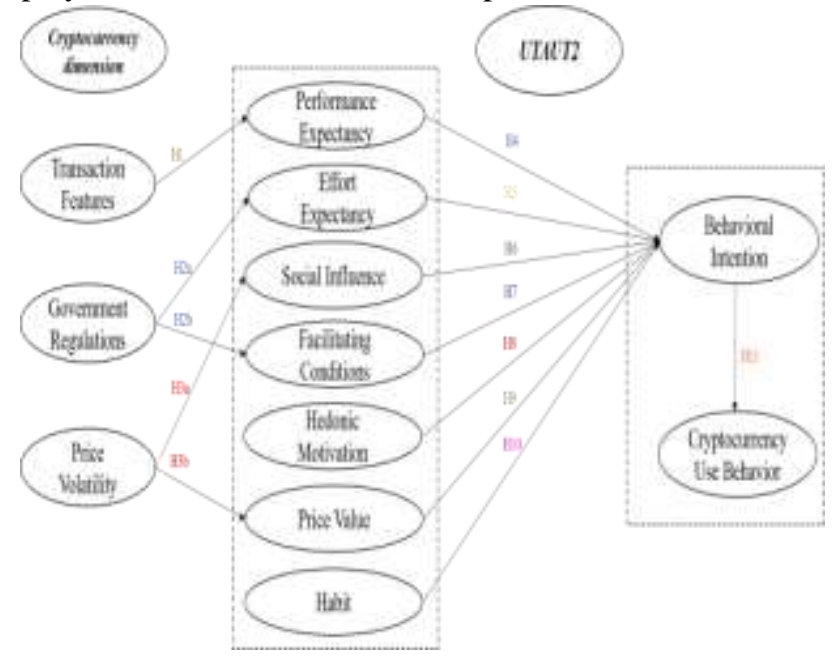

Fig. 1. Proposed conceptual model

\section{B. Hypothesis Development}

Cryptocurrencies are introduced as a new financial means technology. Unlike traditional fiat currency, cryptocurrency system eliminates the need of central authority to control our own money. As compared to the days are taken for a conventional bank to transfer money over long distances, transactions over cryptocurrency's blockchain are completed within a shorter time, nearly instantaneously. In term of transaction security, users have complete control of their own money and thus it is impossible for the third party to take it from their accounts [29]. Overall, the transaction features provided by cryptocurrencies such as intermediaries removal [9, 30], lesser transaction time [28, 31] and lower cost of transfer [9, 31] makes cryptocurrency attractive to users [29] and it is expected to be beneficial for consumers. Hence, this study postulates the following hypothesis:

H1: Cryptocurrency's transaction features (TF) will influence Performance Expectancy (PE) positively.

While cryptocurrency is gaining significant traction due to its potential to revolutionize the way money is exchanged, its legal status remains questionable over countries in such that they are not ready to espouse a standardized global regulatory framework $[32,33]$. Government's position in the cryptocurrency market leads to the current struggling for for paying goods and services leveraging on blockchain

mass acceptance and adoption [34]. In the case of Malaysia, cryptocurrency regulation has come into effects on 15 th January 2019 in which Malaysian government shows their support in encouraging innovations while preventing illicit trading [5]. Since current regulatory mechanisms are in their infancy and cryptocurrency are not universally recognized as legal tender, this study expects that government regulations play an important role in affecting an individual's acceptance. For instance, the prohibited usage of cryptocurrency in certain countries such as China and Russia will influence an individual's effort expectancy in the ease of using cryptocurrency in a worldwide context. In view of the importance of government's role in the establishment of regulations, this study hypothesizes that:

H2a: Cryptocurrency's government regulations (GR) will influence Effort Expectancy (EE) positively.

H2b: Cryptocurrency's government regulations (GR) will influence Facilitating Conditions $(F C)$ positively.

Moreover, the price of cryptocurrency is highly volatile as compared to other financial assets such as stocks [29, 30, 35 ] because its price depends on the total market demand without governmental control. In the case of governmentcontrolled fiat currency system i.e. Malaysian Ringgit (MYR), Bank Rakyat Malaysia is accountable to adjust the supply of MYR based on the changes in accumulated demand for money to achieve price stabilization. However, since central authority is absent in cryptocurrency system, it is inevitable that the cryptocurrency unit has higher shortterm price fluctuations as compared to fiat currency [36]. On one hand, individuals incurs fear and negative sentiment due to its price fluctuations [31]. On another hand, some studies found that investors are significantly attracted to Bitcoin as soon as a major increase in price volatility for monetary gain $[10,34,37]$. This study argues that the cryptocurrency's price volatility will affect a user's perception of the price value of cryptocurrency because its monetary cost fluctuates in line with its price. Hence, the following hypothesis is formed:

H3a: Cryptocurrency's price volatility (PVL) will impact Social Influence (SI) positively.

H3b: Cryptocurrency's price volatility (PVL) will impact Price Value $(P V)$ positively.

Cryptocurrency has appeared as an alternative payment system to the traditional existing financial services which leverage on blockchain technology, it is expected that blockchain technology may be providing prominent benefits to users. To influence the level of cryptocurrency acceptance, it is necessary to acknowledge the usefulness and advantages of cryptocurrency [38, 39]. As such, [9] listed that Bitcoin provides multiple benefits such as enhanced anonymity of digital cashless payment, lower transaction fees, worldwide usage and the opportunity to earn cryptocurrency by mining. With these potential benefits, consumers tend to believe blockchain technology that underlies cryptocurrency is useful and beneficial in 
performing transactions. Therefore, the hypothesis is formed as below:

H4: Performance Expectancy (PE) will have a positive influence on Behavioral Intention (BI) to use cryptocurrency.

Since cryptocurrency can be used as both an investment tool and transactional currency, its usage requires some technical and financial knowledge to use it efficiently and safely [25]. From the financial perspective, consumers should equip themselves with basic financial knowledge in monitoring the price value to avoid unexpectedly high financial loss. From the technical perspective, cryptocurrency users are responsible to secure their wallet which is prone to security attack and the payment transactions are irreversible. Overall, it is anticipated that the necessary knowledge required in using cryptocurrency will feature prominently and thus the higher degree of perceived ease of use will have a positive effect on behavioral intention to adopt cryptocurrency [38-40]. Thus, this study hypothesizes that:

H5: Effort Expectancy (EE) will have a positive influence on Behavioral Intention (BI) to use cryptocurrency.

As a peer-to-peer transaction system with its decentralized nature, cryptocurrency system works without a central authority and therefore its legality remains a debatable topic around the world. The network effects is deemed to contribute to the success of cryptocurrency by expanding the usage of cryptocurrency $[25,41]$. The large the number of cryptocurrency community who willing to recognize the value of cryptocurrency as a transactional currency, the more the non-adopters are encouraged for acceptance and adoption. In other word, cryptocurrency value is driven by social attention which is determined by the amount of people accepting and adopting it as a payment tool. Social factors have been found to have a significant influence on Bitcoin acceptance and adoption [7, 22, 24, 28]. This leads to the following hypothesis:

H6: Social Influence (SI) will have a positive influence on Behavioral Intention (BI) to use cryptocurrency.

Refer to the fifth hypothesis statement, cryptocurrency usage requires basic financial and technical knowledge, thus the availability of facilitations plays an important role in influencing acceptance. To date, though cryptocurrency is not backed by government and there is no standardized guideline for its usage, there is a wide range of discussion forums, social media pages and cryptocurrency-related websites available over the Internet. Virtual cryptocurrency communities and social networks welcome anyone to request for advices and suggestions [39, 42]. This encourages worldwide interaction between experienced users and new users to raise up their inquiries regarding cryptocurrency usage. Therefore, it is anticipated that the behavioral intention to accept cryptocurrency will be positively affected if guidance is in place to facilitate its usage and the following hypothesis statement is then constructed:
H7: Facilitating Conditions (FC) will have a positive influence on Behavioral Intention (BI) to use cryptocurrency.

UTAUT2 covers the importance of both extrinsic and intrinsic motivation which leads to technology acceptance and use. One of the intrinsic motivations in UTAUT2 is hedonic motivation. In view of cryptocurrency as a transactional currency, it can also be used as an investment tool to generate income. People might opt to adopt cryptocurrency for investment purpose to achieve a sense of satisfaction when investment's return is generated. It is believed that user's behavioral intention is positively affected by joyful and happiness the return of cryptocurrency investment provides. This is hypothesized as follows:

H8: Hedonic Motivation (HM) will have a positive influence on Behavioral Intention (BI) to use cryptocurrency.

Unlike organizational context, individual users are fully accountable for the price and cost associated with the purchase of cryptocurrency. As compared to fiat currency, cryptocurrency is relatively unstable because its price is decided by the global market demand and supply. The worth of a specific cryptocurrency unit depends on the perceived trade-off between user's perception on the benefits of using cryptocurrency and its associated monetary cost. Therefore, price value is a significant factor to be taken into consideration in the study of cryptocurrency acceptance and the hypothesis statement is developed as below:

H9: Price Value (PV) will have a positive influence on Behavioral Intention (BI) to use cryptocurrency.

With regard to the context of mobile payment and banking, habit (HB) brings a positive impact towards the use of a new technology [43]. In fact, people are so familiar with fiat currency that regulated by central bank. Generally, all Malaysians have extensive usage experience with paper currency, namely Malaysian Ringgit (MYR), and thus it is significant to evaluate how 'habit' affects Malaysians in accepting cryptocurrency as an intangible payment mechanism. On the other hand, the familiarity of using alternative digital currencies and mobile banking are likely to impact cryptocurrency acceptance [44]. As a novel digital innovation in the financial technologies field, the degree of a consumer utilizes traditional fiat currency automatically in the course of their daily life to exchange for goods and services affects the intention to adopt cryptocurrency. Accordingly, a hypothesis statement is formed as below:

H10: Habit (HB) will have a positive influence on Behavioral Intention (BI) to use cryptocurrency.

To sum up, the cryptocurrency dimension variables and UTAUT2 key constructs contribute to a person's behavioral intention to adopt cryptocurrency. The intention of accepting cryptocurrency will eventually lead to the actual use behavior. Hence, behavioral intention is hypothesized to have a positive effect on cryptocurrency use behavior. 
International conference on Recents Advancements in Engineering and Technology (ICRAET-18) |15th and 16th March 2019|Siddhartha Institute of Technology \& Sciences, Telangana, India.

H11: Behavioral Intention (BI) will have a positive influence on Use Behavior (UB) to use cryptocurrency.

\section{METHODOLOGY}

This section explains the methods used along the process of instrument development, sampling, pilot data examination, and analysis. This research intends to study the influencing factors of cryptocurrency acceptance in the context of Malaysian individuals. To fulfill this purpose, this study adopts a deductive quantitative approach which uses an online survey questionnaire as an effective and low-cost data collection tool. Upon the completion of survey instrument development, cognitive interviews were conducted with four blockchain experts. Then, pilot data were collected by posting the link to the survey questionnaire over a Malaysian cryptocurrency community group on Facebook. Consequently, PLS-SEM analyses were carried out to check the validity and reliability of the questionnaire instrument before a full-scale survey can be conducted.

\section{A. Instrument Development}

Questionnaire items are designed based on the constructs embedded in the proposed conceptual model. The responses are categorized based on a 5-point Likert Scale, in which " 1 " =strongly disagree, " $2 "=$ disagree, " $3 "=$ neutral, " 4 " $=$ agree, and " $5 "=$ strongly agree. The distributed questionnaire is made up of two sections and written in English. In the first section, respondents were asked about demographic information, cryptocurrency knowledge level and actual usage experience. In the second section, it includes questions related to the constructs of the proposed model.

\section{B. Pilot Study}

For self-administered survey questionnaire, it is important to carry out pilot test to verify that the questions are understandable and answered by respondents in the intended manner [45-47]. Before a full-scale survey, a two-stage pilot study had been conducted. For the first stage, this study opts for open-ended retrospective think-aloud cognitive interview [48] to test the questionnaire because (1) this technique has the minimum interjection from the interviewer that avoid interviewer-imposed bias, (2) the respondent's verbalization process is guided minimally in which that unanticipated information may be retrieved and (3) the retrospective approach allows interviewer to observe the ability of respondent to complete the self-administered survey questionnaire. The questionnaire was reviewed by blockchain field experts to recognize the potential problems such as confusion with the meaning, misinterpretation of individual terms, ease of navigation through the questionnaire, and questionnaire format.

For the second stage, the revised questionnaire was distributed to the type of people who will be involved in the main survey. Nevertheless, the respondents involved in pilot study will not be recruited for actual data collection. The main purpose of the second stage of pilot study is to empirically and objectively test the reliability and validity of the survey instrument using the gathered pilot data.

\section{Sampling and Data Collection}

The unit of analysis of this pilot study is the Malaysian individuals who have knowledge about cryptocurrency. This study uses theory to explain a phenomenon in Malaysia context is about theory generalization, rather than sample generalization. Plus, a complete sampling frame is unable to be developed with a complete list of individuals who possess cryptocurrency knowledge due to the decentralized and anonymous nature of cryptocurrency. Therefore, probability sampling is not necessary in this study to achieve sampling generalizability [45, 49]. Non-probabilistic sampling method i.e. purposive sampling is employed to deliberately select respondents from cryptocurrency social media group to answer the questionnaire because these individuals who voluntarily joined these social media groups are deemed to have cryptocurrency knowledge and they are more likely to produce valuable data [49]. As for the sample size of pilot test, [50] suggested a sample between 25 and 100 individual. For this pilot study, a total of 343 questionnaires were distributed to the members of Cryptocurrency Malaysia Facebook Group and 39 of responses were returned which yields a response rate of $11.37 \%$.

\section{Data Analysis Method}

When the first-generation statistical methods (e.g. cluster analysis, multidimensional scaling) assume that the data are error free, the second-generation statistical method (i.e. PLS-SEM) use the measurement model assessment stage to identify the error component of data and remove it from further analysis [51]. It is necessary to address the data collection issue once the empirical data are gathered using questionnaire. Subsequently, 2 responses are removed due to suspicious response pattern (i.e. straight lining) in which only $3 \mathrm{~s}$ and $5 \mathrm{~s}$ are selected, respectively. There is no missing value found among all the responses. Besides, a screening question "Are you Malaysian?" was included to ensure that the respondents meet the prescribed criteria and one response was removed due to the non-Malaysian nationality. In short, 36 responses are kept for data analysis after 3 responses were removed during the data examination phase.

With respect to the descriptive statistics, IBM SPSS Statistics 25 software was used to compute the frequencies and percentages for the respondents' demographic profile [52]. Successively, the reliability and validity of the measurement model is assessed using structural equation modeling (SEM) technique with partial least square (PLS) approach. SmartPLS 3 was used for PLS-SEM analyses [53].

\section{RESULTS AND FINDINGS}

This section presents the findings of the two-stage pilot study. For the first stage of pilot study, the results of cognitive interviews were presented. Whereas for the second stage, the measurement model was evaluated using PLSSEM analyses and the implications were given in the following section. 


\section{A. First Stage Pilot Study: Cognitive Interviews}

During the cognitive interviews, survey questionnaires were distributed to four respondents: Project Director and Business Development Executive of NEM Malaysia Sdn. Bhd., Business Development Manager of Quest Mining Technologies Sdn. Bnd. as well as the Committee Member of ACCESS Blockchain Association. Each interview consumed approximately one hour for respondents to express their feedbacks on the survey.

The cognitive interviews results are categorized into four categories: general format, question interpretation and time frame. From the general format aspect, the respondents express their lack of patience on their first glance on the 6page survey questionnaire. Along the process of answering the survey, the respondents found ambiguous words with no further explanation given. The difficulty in understanding the ambiguous words led to longer time taken to complete the questionnaire. Besides, the respondents expressed that the coverage of contents is too narrow and specific to mention only about Bitcoin, which is biased against other cryptocurrencies. They added that different cryptocurrency has difference characteristics in term of transaction fees, transaction time consumption and level of risk, thus providing different benefits to users. The result of the first stage of pilot study are tabulated in Table I

Table I. Cognitive interview results

\begin{tabular}{|c|c|c|}
\hline Categories & Original item & Revised item \\
\hline $\begin{array}{l}\text { General } \\
\text { format }\end{array}$ & $\begin{array}{l}\text { The number of } \\
\text { questions is appeared } \\
\text { to be too many at first } \\
\text { glance. }\end{array}$ & $\begin{array}{l}\text { The questions are } \\
\text { separated into } 2 \\
\text { sections. }\end{array}$ \\
\hline \multirow[t]{2}{*}{$\begin{array}{l}\text { Question } \\
\text { interpretation }\end{array}$} & $\begin{array}{l}\text { The coverage of } \\
\text { content is too narrow } \\
\text { and only specific to } \\
\text { Bitcoin. }\end{array}$ & $\begin{array}{l}\text { The term "Bitcoin" } \\
\text { is replaced with } \\
\text { "cryptocurrency". }\end{array}$ \\
\hline & $\begin{array}{l}\text { The meaning of words } \\
\text { is ambiguous. } \\
\text { E.g. 1: I find/would } \\
\text { find using Bitcoin } \\
\text { is/could be beneficial. }\end{array}$ & $\begin{array}{l}\text { The questions are } \\
\text { elaborated for } \\
\text { ambiguous words. } \\
\text { E.g. 1: I find/would } \\
\text { find using } \\
\text { cryptocurrency } \\
\text { helps to save time. }\end{array}$ \\
\hline Time frame & $\begin{array}{l}\text { The difficulty in } \\
\text { interpreting the } \\
\text { ambiguous }\end{array}$ & $\begin{array}{l}\text { The questions that } \\
\text { consists r of } \\
\text { ambiguous words }\end{array}$ \\
\hline
\end{tabular}

$\begin{array}{llr}\text { caused respondents } & \text { are } & \text { edited } \\ \text { took approximately } 30 & \text { accordingly } & \text { to } \\ \text { minutes to complete } & \text { provide better } \\ \text { the survey. } & \text { understanding. }\end{array}$

\section{B. Second Stage Pilot Study: Descriptive Statistics}

IBM Statistics SPSS 25 was used for descriptive statistics. Among the respondents, the percentage of male respondents $(94.4 \%)$ is drastically higher than that of female respondents $(5.6 \%)$. Most of the respondents have the age range from $21-30(55.6 \%), 30.6 \%$ were aged between $31-40$, $8.3 \%$ fell into the age group of $41-50$ and $5.6 \%$ of them were above 50. A majority of respondents are holding a bachelor's degree (58.3\%), 25\% of diploma holder, $4 \%$ of secondary school certificate holder, primary school as well as master's degree holder constituted $1 \%$ respectively. With regard of occupation, respondents are mostly working in private sector (15\%) and self-employed (11\%). Most respondents are having an average level of income, $15 \%$ of respondents' income belong the range of RM 2,001 to RM 4,001 and $6 \%$ of respondents' income are ranged between RM 4,001 and RM 6,000.

A valuable finding is that all respondents declared that they have at least a basic understanding of cryptocurrency in which $55.6 \%$ of them even have a thorough understanding and $4 \%$ are subject matter expert. This provides an indication of their credibility in answering the questionnaire for this pilot study. The questionnaire further probe into their actual experience in adopting cryptocurrency, rather than just accepting it. Despite there is $11.1 \%$ of respondents do not own cryptocurrency in real life but their responses are considered credible as they have certain level of cryptocurrency knowledge and the primary purpose of this pilot study paper is just to evaluate the survey instrument. $33.3 \%$ of respondents have 1-2 years of actual usage experience, $25 \%$ have $2-3$ years experiences, $19.4 \%$ have less than 1-year experience and $11.1 \%$ have been using cryptocurrency for more than 3-year. The overall demographic data of the respondents are tabulated in Table II.

Table II. Demographic profile of 36 respondents

\begin{tabular}{lll}
\hline Description & Count & $\%$ \\
\hline Gender & & 5.6 \\
Male & 2 & 94.4 \\
Female & 34 & 55.6 \\
Age & & 30.6 \\
$21-30$ & 20 & 8.3 \\
$31-40$ & 11 & 5.6 \\
$41-50$ & 3 & 2.8 \\
Above 50 & 2 & 11.1 \\
Education level & & \\
Primary school & 1 & \\
Secondary school & 4 & 25.0 \\
Diploma & 9 & \\
\hline
\end{tabular}




\begin{tabular}{lll}
\hline Bachelor's degree & 21 & 58.3 \\
Master's degree & 1 & 2.8 \\
Occupation & 3 & 8.3 \\
Student & 2 & 5.6 \\
Government sector & 15 & 41.7 \\
Private sector & 11 & 30.6 \\
Self-employed & 2 & 5.6 \\
Retired & 3 & 8.3 \\
Others & & \\
Income level & 4 & 11.1 \\
Below RM 2,000 & 15 & 41.7 \\
RM 2,001- RM 4,000 & 6 & 16.7 \\
RM 4,001- RM 6,000 & 4 & 11.1 \\
RM 6,001- RM 8,000 & 2 & 5.6 \\
RM 8,001-RM 10,000 & 5 & 13.9 \\
Above RM 10,000 & & 33.3 \\
Cryptocurrency knowledge level & 12 & 55.6 \\
A basic understanding of the concept and what is it used for & 20 & 11.1 \\
A thorough understanding & 4 & 11.1 \\
Subject matter expert & & 19.4 \\
Cryptocurrency usage experience & 4 & 33.3 \\
None & 7 & 25.0 \\
Less than 1 year & 12 & 11.1 \\
1-2 years & 9 & \\
2-3 years & 4 & \\
More than 3 years & & \\
\hline
\end{tabular}

\section{Measurement Model Analysis}

A multivariate model involves using several measurement items to measure a construct (also known as latent variable or unobserved variable) and it is important to ensure the goodness of measures for the developed research model through reliability and validity test [51]. As such, SmartPLS 3 was used to evaluate the measurement model by assessing

Table III, it is evident that the loadings of indicator gr_2 was slightly

lower than the threshold value of 0.708 . Since indicators with loadings lower than 0.708 can be kept when the AVE the internal consistency reliability, indicator reliability, convergent reliability and discriminant validity.

To assess the measurement model, 2 types of validity tests need to be conducted, which are convergent validity and discriminant validity. For convergent validity, the loadings of measurement items and the average variance extracted (AVE) need to be measured. Based on result of minimum 0.5 has achieved [54] as well as the negligibly low loadings of gr_2, this indicator is retained However, the indicators tf_1, si_2 and fc_1 are eliminated because their loadings are significantly low. All the constructs have reached the satisfactory level of AVE value higher than 0.5. Meanwhile, the composite reliability (CR) of all constructs have met the acceptable value of higher than 0.7 . In sum, both reliability and convergent validity of the measures are established.

Table III. Results of constructs' reliability and convergent validity analysis

\begin{tabular}{|c|c|c|c|c|}
\hline \multirow[t]{2}{*}{ Construct } & \multirow[t]{2}{*}{ Item } & \multicolumn{3}{|c|}{ Assessment/ Name of index } \\
\hline & & Loadings & AVE & CR \\
\hline \multirow[t]{2}{*}{$\mathrm{TF}$} & tf_2 & 0.853 & 0.810 & 0.895 \\
\hline & tf_-3 & 0.913 & & \\
\hline \multirow[t]{2}{*}{ GR } & gr_1 & 0.985 & 0.732 & 0.841 \\
\hline & gr_2 & 0.698 & & \\
\hline PVL & pvl_1 & 1.000 & 1.000 & 1.000 \\
\hline \multirow[t]{4}{*}{ PE } & pe_1 1 & 0.528 & 0.601 & 0.854 \\
\hline & pe_2 & 0.845 & & \\
\hline & pe_3 & 0.848 & & \\
\hline & pe_4 & 0.831 & & \\
\hline $\mathrm{EE}$ & ee_1 & 0.941 & 0.900 & 0.948 \\
\hline
\end{tabular}




\begin{tabular}{|c|c|c|c|c|}
\hline & ee_2 & 0.957 & & \\
\hline SI & si_1 & 1.000 & 1.000 & 1.000 \\
\hline \multirow[t]{3}{*}{ FC } & fc_2 & 0.877 & 0.771 & 0.910 \\
\hline & fc_3 & 0.903 & & \\
\hline & fc_4 & 0.797 & & \\
\hline \multirow[t]{2}{*}{ PV } & pv_1 & 0.775 & 0.631 & 0.773 \\
\hline & pv_2 & 0.813 & & \\
\hline \multirow[t]{2}{*}{$\mathrm{HM}$} & hm_1 & 0.921 & 0.819 & 0.901 \\
\hline & hm_2 & 0.889 & & \\
\hline \multirow[t]{2}{*}{ HB } & hb_1 & 0.958 & 0.896 & 0.945 \\
\hline & hb_2 & 0.934 & & \\
\hline BI & bi_1 & 1.000 & 1.000 & 1.000 \\
\hline CUB & cub_1 & 1.000 & 1.000 & 1.000 \\
\hline
\end{tabular}

* Note: Items tf_1, si_2 and fc_1 are removed due to low loadings.

On the other hand, to achieve discriminant validity of the model, the measurement items should load more strongly on their own constructs as compared to other constructs in the model. Also, the average variance shared between each construct and its measures should be greater than the variance shared between the constructs and other constructs [55]. Simple stated, referred to

Table $\mathbf{V}$, the square of AVE (i.e. the diagonal value in bold) is greater than the correlations of all constructs (i.e. the off-diagonal value without in bold). This indicates that the discriminant validity of all constructs has achieved a satisfactory level.

While the Fornell-Larcker Criterion has been widely used as the dominant approach for the evaluation of discriminant validity, [56] criticized on its problem of low sensitivity in which the discriminant validity problems are largely remained as undetected. Hence, a new criterion has been developed to assess discriminant validity: the heterotraitmonotrait ratio of correlations (HTMT) [56]. Draw on the first HTMT results as shown in

Table V, the inter-construct correlations of hedonic motivation (HM) and price value (PV) neither meeting the HTMT.90 criterion [57] nor the HTMT.85 criterion [58]. The value of 1.132 which is higher than the required threshold value of the aforementioned criterions indicates a lack of discriminant validity for the constructs.

A possible solution recommended by [56] is to decrease the heterotrait-heteromethod correlations by removing an item with high cross-item correlations. After the indicator pv_1 is removed, discriminant validity has been successfully established by having all the values lower than the required threshold value of both HTMT.90 criterion and HTMT0.85 criterion, as shown in

\section{Table VI.}

To further evaluate the discriminant validity, HTMT inferential can be performed using bootstrapping technique. In this assessment, the null hypothesis (H0: HTMT >=1) is tested against the alternative hypothesis $(\mathrm{H} 1$ : HTMT<1) in which the confidence interval should not include a result of 1 to establish discriminant validity [56]. The findings of this pilot study present that the lower and upper confidence intervals do not include a value of 1 at a significance level of 0.10 and a bootstrapping of 500 samples. As a result, the adequacy of discriminant validity is confirmed.

\section{DISCUSSION}

This pilot study employed PLS-SEM analyses to test the goodness of measures of the proposed research model that aims to examine the factors influence the intention to adopt cryptocurrency. The developed survey questionnaire was reviewed by four field experts and a subsequent pilot study was conducted to evaluate its reliability and validity. Upon the completion of first-stage pilot study, questionnaire was amended according to the feedbacks of field experts. Through the means of online questionnaire, second stage pilot data was then collected from the individuals who joined the Facebook group of "Cryptocurrency Malaysia" because they are deemed to have adequate cryptocurrency knowledge for responding the questionnaire.

Accordingly, 36 responses were analyzed using SmartPLS to evaluate the reliability and validity of measures and constructs embedded in the proposed research model. Based on the findings of measurement model assessment, 4 measurement items were removed from the pilot questionnaire in which still adhering to the rule of not eliminating more than $20 \%$ of the total indicators [54]. Consequently, the altered instrument has exhibited a satisfactory and acceptable level of reliability and credibility by looking at 4 indices, including outer loadings, composite reliability (CR), average variance extracted (AVE) and discriminant validity. In another words, this reliable and valid instrument can then be used for actual data collection.

Similar to other studies, this pilot study is not without its limitations. First, the collected sample size is relatively small and thus it does not meet the minimum sample size requirement to conduct structural model assessment for hypothesized relationships testing. Nevertheless, the small sample size is adequate to achieve the goal of study which is evaluating the reliability and validity of the survey instrument items and the constructs of proposed research model. Gpower software can be used to determine the minimum sample size required for actual data collection [59, 60]. While the maximum number of arrows pointing at an endogenous construct is 7 and the effect size $\left(f^{2}\right)$ is estimated to be relatively small at 0.05 , the actual data collection phase requires a minimum sample size of 295 to achieve a statistical power of $80 \%$ with a $5 \%$ probability of error. 
Second, this pilot study only collected data by the means of a cryptocurrency community group on Facebook. Despite the pilot study data is only collected from one cryptocurrency community group, all the gathered responses are valuable and credible as the respondents are those who have considerable level of cryptocurrency knowledge. The survey questionnaire will be broadcasted to other channels during actual data collection phase.

Table IV. Results of discriminant validity analysis using Fornell-Larcker Criterion

\begin{tabular}{|c|c|c|c|c|c|c|c|c|c|c|c|c|}
\hline & BI & CUB & $\mathrm{EE}$ & $\mathrm{FC}$ & GR & $\mathrm{HB}$ & $\mathrm{HM}$ & $\mathrm{PE}$ & $\mathrm{PV}$ & PVL & SI & $\mathrm{TF}$ \\
\hline BI & 1.000 & & & & & & & & & & & \\
\hline CUB & 0.368 & 1.000 & & & & & & & & & & \\
\hline $\mathrm{EE}$ & 0.229 & 0.395 & 0.949 & & & & & & & & & \\
\hline $\mathrm{FC}$ & 0.612 & 0.420 & 0.260 & 0.878 & & & & & & & & \\
\hline GR & -0.151 & 0.118 & 0.290 & -0.107 & 0.855 & & & & & & & \\
\hline HB & 0.663 & 0.671 & 0.391 & 0.634 & 0.039 & 0.946 & & & & & & \\
\hline HM & 0.446 & 0.548 & 0.274 & 0.509 & -0.146 & 0.518 & 0.905 & & & & & \\
\hline PE & 0.215 & 0.421 & 0.631 & 0.193 & 0.425 & 0.439 & 0.181 & 0.775 & & & & \\
\hline PV & 0.508 & 0.379 & 0.405 & 0.457 & 0.225 & 0.466 & 0.640 & 0.360 & 0.794 & & & \\
\hline PVL & 0.295 & 0.032 & 0.062 & -0.059 & -0.178 & 0.054 & 0.032 & -0.175 & 0.093 & 1.000 & & \\
\hline SI & 0.381 & 0.396 & 0.358 & 0.594 & 0.100 & 0.716 & 0.292 & 0.431 & 0.336 & -0.111 & 1.000 & \\
\hline TF & 0.184 & 0.196 & 0.216 & 0.016 & 0.224 & 0.251 & 0.054 & 0.534 & -0.015 & -0.065 & 0.251 & 0.900 \\
\hline
\end{tabular}

Table V. Results of discriminant validity analysis using HTMT Criterion (first analysis)

\begin{tabular}{llllllllllll}
\hline & BI & CUB & EE & FC & GR & HB & HM & PE & PV & PVL & SI \\
\hline BI & & & & & & & & & & & \\
CUB & 0.368 & & & & & & & & & & \\
EE & 0.251 & 0.425 & & & & & & & & & \\
FC & 0.652 & 0.457 & 0.301 & & & & & & & & \\
GR & 0.139 & 0.163 & 0.313 & 0.269 & & & & & & & \\
HB & 0.697 & 0.708 & 0.446 & 0.707 & 0.228 & & & & & & \\
HM & 0.502 & 0.626 & 0.340 & 0.614 & 0.148 & 0.613 & & & & & \\
PE & 0.250 & 0.502 & 0.776 & 0.279 & 0.491 & 0.532 & 0.261 & & & & \\
PV & 0.787 & 0.597 & 0.692 & 0.772 & 0.377 & 0.759 & 1.132 & 0.670 & & & \\
PVL & 0.295 & 0.032 & 0.096 & 0.132 & 0.252 & 0.056 & 0.039 & 0.284 & 0.147 & & \\
SI & 0.380 & 0.396 & 0.382 & 0.644 & 0.190 & 0.759 & 0.320 & 0.496 & 0.520 & 0.111 & \\
TF & 0.155 & 0.227 & 0.258 & 0.090 & 0.241 & 0.290 & 0.133 & 0.684 & 0.236 & 0.148 & 0.290 \\
\hline
\end{tabular}

Table VI. Results of discriminant validity analysis using HTMT Criterion (second analysis)

\begin{tabular}{llllllllllll}
\hline & BI & CUB & EE & FC & GR & HB & HM & PE & PV & PVL & SI \\
\hline BI & & & & & & & & & & & \\
CUB & 0.368 & & & & & & & & & & \\
EE & 0.251 & 0.425 & & & & & & & & & \\
FC & 0.652 & 0.457 & 0.301 & & & & & & & & \\
GR & 0.139 & 0.163 & 0.313 & 0.269 & & & & & & & \\
HB & 0.697 & 0.708 & 0.446 & 0.707 & 0.228 & & & & & & \\
HM & 0.502 & 0.626 & 0.340 & 0.614 & 0.148 & 0.613 & & & & & \\
PE & 0.250 & 0.502 & 0.776 & 0.279 & 0.491 & 0.532 & 0.261 & & & & \\
PV & 0.427 & 0.201 & 0.074 & 0.487 & 0.203 & 0.323 & 0.489 & 0.124 & & & \\
PVL & 0.295 & 0.032 & 0.096 & 0.132 & 0.252 & 0.056 & 0.039 & 0.284 & 0.038 & & \\
SI & 0.380 & 0.396 & 0.382 & 0.644 & 0.190 & 0.759 & 0.320 & 0.496 & 0.282 & 0.111 & 0.290 \\
TF & 0.155 & 0.227 & 0.258 & 0.090 & 0.241 & 0.290 & 0.133 & 0.684 & 0.129 & 0.148 & 0.129 \\
\hline
\end{tabular}

\section{CONCLUSION}

The increasing significance of cryptocurrency and blockchain technology has created intense research attention in various disciplines, especially within the information technology, finance and economics domain. While the amount of cryptocurrency acceptance studies in developing countries context is relatively scarce, this study comes into place to analyze cryptocurrency acceptance factors in Malaysia from the IS perspective. While existing literature proved that the weakness of UTAUT2 model is the recency of the model and the usage is not widespread for alternate new technologies, this study conceptualizes and proposes a conceptual model that integrates UTAUT2 constructs with cryptocurrency dimension variables. The conceptualized model is designed to consider cryptocurrency's characteristics which enables researchers and practitioners to gain insights into the influencing factors towards the acceptance and intention to use cryptocurrency.

On top of that, a pilot study had been carried out to verify the reliability and validity of the survey instrument via PLSSEM analyses. Future work can be done on a full-scale survey so that the structural model relationships can be tested. In a nutshell, the findings of this paper are expected to make theoretical and practical contributions to the body of knowledge and cryptocurrency stakeholders. The expected contributions are included, but not limited to: (1) a high-level overview of potential factors that influence cryptocurrency acceptance, (2) a reliable and valid survey instrument to study cryptocurrency acceptance, (3) a 
preliminary validation of UTAUT2 constructs to be employed in cryptocurrency context, and (4) the proposed model with additional antecedents contributes a new insight to the IS research stream in the study of cryptocurrency acceptance.

\section{REFERENCES}

1. Toh, K.I., Digital economy expected to show significant growth. The Star, 2018.

2. Du, W.D., et al., Affordances, Experimentation and Actualization of FinTech: A Blockchain Implementation Study. Journal of Strategic Information Systems, 2018.

3. Hileman, G. The Bitcoin Market Potential Index. in International Conference on Financial Cryptography and Data Security. 2015.

4. Zulhuda, S. and A.B. Sayuti, Whither Policing Cryptocurrency in Malaysia? Iium Law Journal, 2017. 25: p. 179-196.

5. Zmudzinski, A. Malaysian Cryptocurrency Regulation to Classify Digital Assets, Tokens as Securities. 2019 [cited 2019 1st February]; Available from: https://cointelegraph.com/.

6. Mattke, J., et al. Bitcoin Resistance Behavior: A QCA Study Explaining Why Individuals Resist Bitcoin as a Means of Payment. in 39th International Conference on Information Systems. 2018. San Francisco.

7. Roos, C., The motivation and factors driving cryptocurrency adoption in SMEs, in Gordon Institute of Business Science. 2015, University of Pretoria. p. 1-114.

8. Wahl, F., Adoption of Blockchains - A Cross Cultural Comparison. 2016, University Kasssel. p. 1-30.

9. Ermakova, T., et al., Bitcoin : Drivers and Impediments. SSRN Electronic Journal, 2016. 2: p. 1-18.

10. Henry, C.S., K.P. Huynh, and G. Nicholls, Bitcoin Awareness and Usage in Canada. Journal of Digital Banking, 2018. 2: p. 311-337.

11. Kick, A. and A.J. Connolly. Bitcoin research past, present and future. in 11th Annual USC Upstate Research Symposium. 2015.

12. Glaser, F., et al. Bitcoin-Asset or curreny? Revealing users' hidden intentions. in Proceedings of the European Conference on Information Systems (ECIS). 2014. Tel Aviv, Israel.

13. Morisse, M. Cryptocurrencies and Bitcoin: Charting the Research Landscape. in 31st Americas Conference on Information Systems. 2015. Puerto Rico.

14. Crosby, M., et al., Blockchain Technology: Beyond Bitcoin. Applied Innovation Review, 2016(2): p. 19.

15. Nakamoto, S., Bitcoin: A Peer-to-Peer Electronic Cash System. 2008.

16. Taherdoost, H., A review of technology acceptance and adoption models and theories. Procedia Manufacturing, 2018. 22: p. 960-967.

17. Venkatesh, V., et al., User Acceptance of Information Technology: Toward a Unified View. MIS Quarterly, 2003. 27: p. 425-478.

18. Venkatesh, V., J. Thong, and X. Xu, Consumer acceptance and user of information technology: Extending the unified theory of acceptance and use of technology. MIS Quarterly, 2012. 36: p. 157-178.

19. Ravangard, R., et al., Development of the UTAUT2 model to measure the acceptance of medical laboratory portals by patients in Shiraz. Electronic Physician, 2017. 9: p. 3862-3869.

20. orge, A.-G., P.-P. Begoña, and A.R.-J. Maria, Elderly and internet banking: An application of UTAUT2. Journal of Internet Banking and Commerce, 2015. 20: $\mathrm{p}$. 1-23.

21. Kraljić, A. and A. Peštek, An Application of Utaut2 Model in Exploring the Impact of Quality Of Technology on Mobile Internet. Journal of Economics and Business, 2016. XIV(2): p. 66-77.

22. Moura, A.C.d., et al., Acceptance and use of technology by older adults for choosing a tour-ism destination: a study using UTAUT2. Brazilian Journal of Tourism Research, 2017. 11: p. 239-269.

23. Ain, N., K. Kaur, and M. Waheed, The Influence of Learning Value On Learning Management System Use: An Extension of UTAUT2. Information Development, 2016. 32: p. 1306-1321.

24. Jakkaew, P. and S. Hemrungrote. The use of UTAUT2 model for understanding student perceptions using Google Classroom: A case study of Introduction to Information Technology course. in International Conference on Digital Arts, Media and Technology. 2017.

25. Mahomed, N., Understanding consumer adoption of cryptocurrencies, in Gordon Institute of Business Science. 2017, University of Pretoria. p. 139.

26. Nseke, P., How Crypto-Currency Can Decrypt the Global Digital Divide: Bitcoins a Means for African Emergence. International Journal of Innovation and Economic Development, 2018. 3: p. 61-70.

27. Bagozzi, R., The Legacy of the Technology Acceptance Model and a Proposal for a Paradigm Shift. Journal of the Association for Information Systems, 2007. 8: p. 244254.

28. Gunawan, F.E. and R. Novendra, An Analysis of Bitcoin Acceptance in Indonesia. ComTech: Computer, Mathematics and Engineering Applications, 2017. 8: p 241.

29. Folkinshteyn, D. and M. Lennon, Braving Bitcoin : A Technology Acceptance Model Analysis. Journal of Information Technology Case and Application Research, 2017. 18: p. 220-249.

30. Walton, A. and K. Johnston, Exploring Perceptions of Bitcoin Adoption: The South African Virtual Community Perspective. Interdisciplinary Journal of Information, Knowledge, and Management, 2018. 13: p. 165-182.

31. Baur, A.W., et al., Cryptocurrencies as a disruption? empirical findings on user adoption and future potential of Bitcoin and Co, in Conference on e-business, eservices and e-society. 2015. p. 63-80.

32. Bollen, R. The Legal Status of Online Currencies - Are Bitcoins the Future. in Financial Institutions, Regulation \& Corporate Governance (FIRCG) Conference. 2016. Melbourne Business School.

33. Pieters, G. and S. Vivanco, Financial regulations and price inconsistencies across Bitcoin markets. Information Economics and Policy, 2017. 39: p. 1-14.

34. Farell, R., An Analysis of the Cryptocurrency Industry. 2015, Wharton Research Scholars Journal: University of Pennsylvania.

35. Shahzad, F., et al., An empirical investigation on the adoption of cryptocurrencies among the people of mainland China. Technology in Society, 2018. 55: p. 3340.

36. Berentsen, A. and F. Schär, A short introduction to the world of cryptocurrencies. Federal Reserve Bank of St. Louis Review, First Quarter 2018, 2018. 100(1): p. 1-16.

37. Urquhart, A., What causes the attention of Bitcoin ? Economics Letters, 2018. 166: p. 40-44.

38. Kumpajaya, A. and W. Dhewanto, The acceptance of Bitcoin in Indonesia: Extending TAM with IDT. Journal of Business and Management, 2015. 4: p. 28-38.

Published By:

Blue Eyes Intelligence Engineering

\& Sciences Publication 
39. Silinskyte, J., Understanding Bitcoin adoption: Unified Theory of Acceptance and Use of Technology (UTAUT) application. 2014, Leiden Institute of Advanced Computer Sciences, University Leiden. p. 56.

40. Abramova, S. and R. Böhme. Perceived Benefit and Risk as Multidimensional Determinants of Bitcoin Use: A Quantitative Exploratory Study. in Proceedings of the 37th International Conference on Information Systems (ICIS 2016). 2016.

41. Rodenrijs, N. and J. Wokke, Will social media make or break the acceptance in new technology? A quantitative study of consumer acceptance in cryptocurrency. 2018, Jonkoping International Business School. p. 1-85.

42. Mendoza-Tello, J.C., et al., Social Commerce as a Driver to Enhance Trust and Intention to Use Cryptocurrencies for Electronic Payments. IEEE Access, 2018. 6: p. 50737-50751.

43. Manaf, N.R. and M. Ariyanti, Exploring Key Factors on Technology Acceptance of Mobile Payment Users in Indonesia Using Modified Unified Theory of Acceptance and Use of Technology (Utaut) Model Use Case: Abc Easy Tap. International Journal of Management and Applied Science, 2017. 3(1): p. 40-44.

44. Hutchison, M., Acceptance of Electronic Monetary Exchanges, Specifically Bitcoin, by Information Security Professionals: A Quantitative Study Using the Unified Theory of Acceptance and Use of Technology (UTAUT) Model. 2017, Colorado Technical University: ProQuest. p. 107.

45. Memon, M.A., et al., A Review of The Methodological Misconceptions and Guidelines related to the Application of Structural Equation Modeling: A Malaysian Scenario. Journal of Applied Structural Equation Modeling, 2017. 1(1).

46. Perneger, T.V., et al., Sample size for pre-tests of questionnaires. Qual Life Res, 2015. 24(1): p. 147-51.

47. Sekaran, U. and R. Bougie, Research Methods for Business. A Skill-Building Approach. 2016, United Kingdom: John Wiley \& Sons Ltd.

48. Willis, G., B, Analysis of the Cognitive Interview in questionnaire design. 2015: Oxford University Press.

49. Rowley, J., Designing and using research questionnaires. Management Research Review, 2014. 37(3): p. 308-330.

50. Cooper, D.R. and P.S. Schindler, Business Research Methods. 12th edition ed. 2014: McGraw-Hill.

51. Hair, J.F., et al., A Primer on Partial Least Squares Structural Equation Modeling (PLS-SEM). 2nd ed. 2017: SAGE.

52. IBMCorp, IBM SPSS Statistics for Windows. 2017, IBM Corp: Armonk, New York.

53. Ringle, C.M., S. Wende, and J.-M. Becker. SmartPLS 3 2015; Available from: www.smartpls.com.

54. Ramayah, T., et al., Partial Least Squares Structural Equation Modeling (PLS-SEM) using SmartPLS 3.0. 1st ed. 2016, Malaysia: Pearson Malaysia Sdn Bhd.

55. Fornell, C. and D.F. Larcker, Evaluating Structural Equation Models with Unobservable Variables and Measurement Error. Journal of Marketing Research, 1981. 18(1)

56. Henseler, J., C.M. Ringle, and M. Sarstedt, A new criterion for assessing discriminant validity in variancebased structural equation modeling. Journal of the Academy of Marketing Science, 2015. 43(1): p. 115-135.

57. Gold, A.H., A. Malhotra, and A.H. Segars, Knowledge Management: An Organizational Capabilities Perspective. Journal of Management Information Systems, 2001. 18(1): p. 185.

58. Kline, R.B., Principles and Practice of Structural Equation Modeling. 2011: Guilford Press.
59. Faul, F., et al., $G^{*}$ Power 3: A flexible statistical power analysis program for the social, behavioral, and biomedical sciences. Behavior Research Methods, 2007. 39(2): p. 175-191.

60. Faul, F., et al., Statistical power analyses using $G^{*}$ Power 3.1: tests for correlation and regression analyses. Behavior Research Methods, 2009. 41(4): p. 1149-60.

\section{AUTHORS PROFILE}

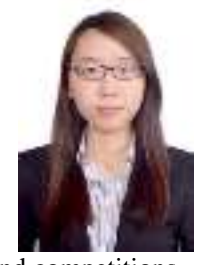

Yoon-Chow Yeong is a MSc degree student in information Systems at the Computer and Information Sciences Department of the Universiti Teknologi PETRONAS (UTP), Malaysia. Her current research interests focus on blockchain, peer-to-peer financing, mobile payment, Industry 4.0, including the adoption and use of technological innovations. She also participated in international exhibitions, conferences
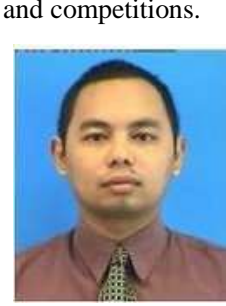

Ts. Dr Khairul Shafee Kalid is a senior lecturer from Computer and Information Systems department, Universiti Teknologi PETRONAS (UTP), Malaysia. Prior, he completed his PhD in Information Technology from UTP in 2015. His research area is information systems. His current research interests focus on the use of tools and techniques in supporting knowledge management as well as the implication of big data in knowledge management. Dr Khairul has published numerous papers in journals and conference proceedings in the area of knowledge management. Also, he has been the principal investigator to two university research grants and two national level grants and a member to five other research projects.

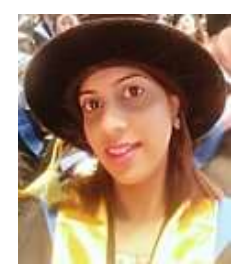

Ts. Dr Savita K Sugathan is a lecturer from Computer and Information Systems department, Universiti Teknologi PETRONAS (UTP), Malaysia. She received her $\mathrm{PhD}$ in information technology from UTP in 2018 and her MSc in technology management from University of New Wales, Sydney, Australia is 2006. Dr Savita is accredited by Malaysia Board of Technologies (MBOT) as Professional Technologist (Ts.) in Information and Computing Technology. She is also a member of Association of Information Systems (AIS), Pertubuhan Sistem Maklumat (PSM/myAIS), Information System Audi and Control Association (ISACA) and Energy Institute. Her research interest is on the Adoption, Implementation and Impact of Technology Advancements towards Sustainable Development which includes the fields of Education, Health and Manufacturing. 